\title{
Spondylocostal dysostosis
}

\section{D YOUNG AND J R MOORE}

Department of Child Health, Leicester Royal Infirmary, Leicester LE2 7LX.

SUMMARY A female child with multiple vertebral and rib abnormalities is described.

Skeletal abnormalities localised to the spine and ribs have been recorded under various headings which include 'spondylocostal dysplasia', 'spondylothoracic dysplasia', 'spondylocostal dysostosis', 3 and 'costovertebral dysplasia.' ${ }^{4}$ Individually these conditions are rare and await full delineation. In this report a relatively mild form is described in the 5year-old daughter of consanguineous parents. No previous report of this condition in the United Kingdom has been traced.

\section{Case report}

The patient is the first child of healthy Caucasian parents who are first cousins. She has one normal younger brother and there is no family history of

Received for publication 27 June 1983.

Accepied for publication 20 August 1983.

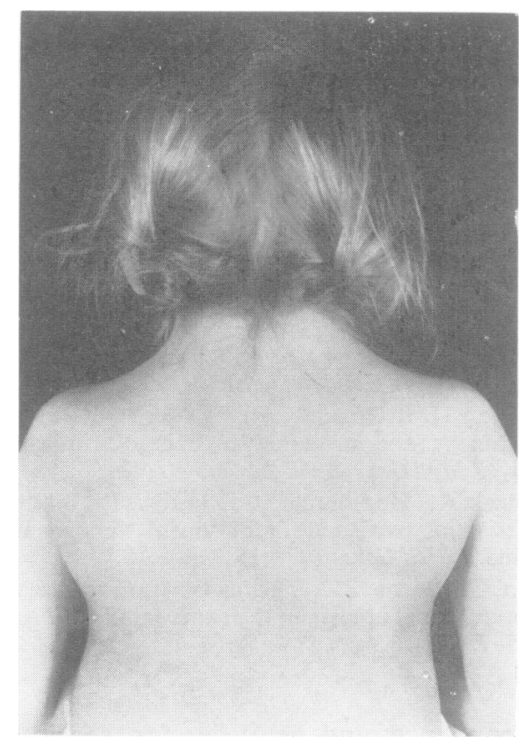

FIG 1 The patient aged 5 years. Note her short webbed neck and low posterior hair line. spinal abnormality. She was born by forceps delivery $\frac{\bar{c}}{\bar{c}}$ following an uneventful drug-free pregnancy with birth weight $3.2 \mathrm{~kg}$. Her development has teen normal. She has had no serious illnesses, nor hases she had symptoms associated with her spinal $\overrightarrow{0}$ abnormality.

On examination at $5 \frac{1}{2}$ years she presented as aw very attractive little girl with weight and heads circumferences on the 10th centile, while her height of $97.7 \mathrm{~cm}$ fell $3 \mathrm{~cm}$ below the 3rd centile. Her upperit to lower segment ratio was 0.92 and her span was. $107 \mathrm{~cm}$. She had a short webbed neck with a low hairos line, an asymmetrical thorax, and a mild scoliosiso (fig 1). She showed no other evidence of skeletal? abnormality and had no neurological deficit.

Chromosome analysis revealed a normal female karyotype. Radiographs showed multiple abnormalities of the vertebral bodies with hemivertebrae, fused

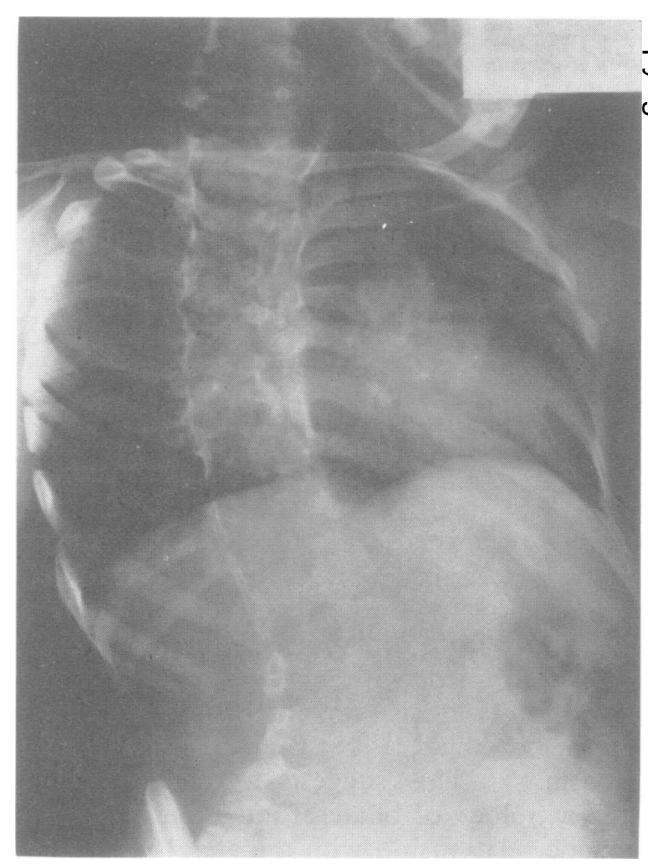

FIG 2 Oblique view of the chest at the age of $3 \frac{1}{2}$ years showing widespread errors of segmentation and fusion in the thoracic vertebrae with associated rib anomalies. 


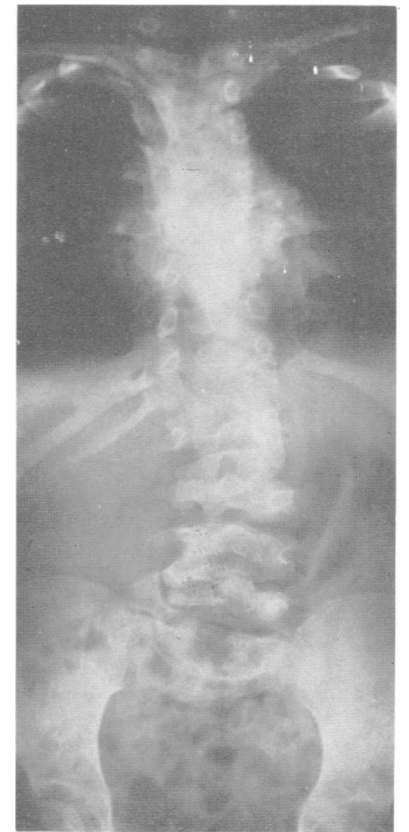

FIG 3 Anteroposterior view of the spine at the age of $3 \frac{1}{2}$ years.

vertebrae, and fusion and bifurcation of the ribs (fig 2). These errors of segmentation and fusion extended throughout the vertebral column (fig 3). There were 11 ribs on the right and nine on the left.

Spinal $x$-rays of the parents were normal.

\section{Discussion}

On clinical and genetic grounds it is possible to distinguish at least three different forms of spondylocostal dysostosis. In the autosomal dominant form, multiple errors of segmentation in the vertebrae are associated with aplasia, hypoplasia, and fusion of the ribs. ${ }^{15}$ Affected subjects are short but otherwise the disorder appears to run a benign course. In contrast, patients with the severe autosomal recessive form of this condition tend to succumb in infancy or early childhood to pneumonia. ${ }^{67}$ These children have a very short neck and trunk, a prominent thorax, and a reduced number of ribs which fuse posteriorly to give a characteristic crab-like appearance on chest $x$-ray. Many of the reported cases are in Puerto Rican families.

In the third form, inheritance is autosomal reces- sive and clinical problems are few. ${ }^{2}{ }^{8-10}$ The radiological findings are almost identical to those seen in the autosomal dominant type. The clinical, genetic, and $x$-ray features in the child described here suggest that she is likely to have this relatively mild third form of spondylocostal dysostosis. Despite the bizarre appearance of the spine in these subjects, the integrity of the spinal cord does not seem to be compromised. However, it would seem prudent to monitor neurological function carefully in these patients.

The radiological abnormalities in this group of disorders differ from those in the much more common neural tube defects, in that they extend throughout the spinal column. This case is presented not only to add to the very sparse literature on this subject, but also to stress the importance of distinguishing between spondylocostal dysostosis and a neural tube defect if correct genetic advice is to be given.

\section{References}

1 Rimoin DL, Fletcher BD, McKusick VA. Spondylocostal dysplasia. A dominantly inherited form of short-trunked dwarfism. Am J Med 1968;45:948-53.

2 Castroviejo IP, Rodriguez-Costa T, Castillo F. Spondylothoracic dysplasia in three sisters. Dev Med Child Neurol 1973;15:348-54.

3 Casamassima AC, Morton CC, Nance WE, et al. Spondylocostal dysostosis associated with anal and urogenital anomalies in a Mennonite sibship. Am J Med Genet $1981 ; 8: 117-27$.

${ }^{4}$ Bartsocas CS, Kiossoglou KA, Papas CV, XanthouTsingoglou M, Anagnostakis DE, Daskalopoulou HD. Costovertebral dysplasia. Birth Defects 1974;10:221-6.

5 Van Der Sar A. Hereditary multiple hemivertebrae. Dos Med Geographica et Tropica 1952;4:23-8.

6 Jarcho S, Levin PM. Hereditary malformation of the vertebral bodies. Bull Johns Hopkins Hosp 1938;62:216-26.

; Pérez-Comas A, García-Castro JM. Occipito-facialcervico-thoracic-abdomino-digital dysplasia: JarchoLevin syndrome of vertebral anomalies. J Pediatr 1974; 85:388-91.

8 Norum RA. Costovertebral anomalies with apparent recessive inheritance. Birth Defects 1969;5:326-9.

9 Caffey J. The vertebra! column. In: Pediatric $x$-ray diagnosis. 6th ed. Chicago: Year Book Medical Publishers, 1973:1361-2.

${ }^{10}$ Silengo MC, Cavallaro S, Franceschini P. Recessive spondylocostal dysostosis: two new cases. Clin Genet 1978;13:289-94.

Correspondence and requests for reprints to Dr I D Young, Department of Child Health, Leicester Royal Infirmary, PO Box 65, Leicester LE2 7LX. 